\title{
Diode-pumped Alexandrite laser for next generation satellite-based earth observation lidar
}

\author{
Michael Strotkamp ${ }^{1}$ (D) Alexander Munk ${ }^{1} \cdot$ Bernd Jungbluth $^{1} \cdot$ Hans-Dieter Hoffmann ${ }^{1} \cdot$ Josef Höffner $^{2}$
}

Received: 20 February 2019 / Revised: 13 May 2019 / Accepted: 15 May 2019 / Published online: 25 May 2019

(c) The Author(s) 2019

\begin{abstract}
In this work, the design of a diode-pumped Alexandrite ring laser in Q-switched single-longitudinal-mode (SLM) operation for a spaceborne lidar mission is presented. The laser is pumped by a self-developed fiber-coupled laser diode pump device and yields a pulse energy of $1.7 \mathrm{~mJ}$ at a repetition rate of $500 \mathrm{~Hz}$ with an excellent beam quality of $M^{2}<1.1$. By seeding the resonator with a narrow band diode laser, SLM operation with a linewidth of approximately $10 \mathrm{MHz}$ is achieved. The electrooptical efficiency of 2\% is the highest achieved for all Alexandrite lasers in SLM operation and reasonable for space operation. The performance analysis as well as benchmarking with the space-qualified mounting technology points out the TRL and the remaining effort for the development of the technology. An estimation of the requirements for a spaceborne resonance lidar mission underlines the suitability of such a lidar system with a diode-pumped Alexandrite laser as the beam source.
\end{abstract}

Keywords Alexandrite laser · Diode-pumped laser · Ring laser · Single-longitudinal-mode laser · Q-switched laser · Tunable laser $\cdot$ Spaceborne laser $\cdot$ Lidar

\section{Introduction}

Understanding temperature distributions and wind fields in the atmosphere at altitudes between 80 and $110 \mathrm{~km}$, i.e., the mesosphere and lower thermosphere (MLT), is crucial for performing numerical simulations of the Earth's climate. The effects of gravity waves on the global wind system and atmospheric dynamics are hardly understood and item of research of space agencies and ground-based observations [1-6]. One well-established approach to provide such data is to measure the Doppler-broadened and Doppler-shifted resonance line of metal atoms, e.g., potassium $(770 \mathrm{~nm}$ or $766 \mathrm{~nm})[6,7]$, iron $(386 \mathrm{~nm}$ or $372 \mathrm{~nm})[8,9]$ and sodium $(589 \mathrm{~nm})$ [10-12], by means of a Doppler lidar.

While localized measurements have been performed over the last 20 years from the ground and revealed fundamental deviations from the predicted conditions, there is no coverage of global scale by lidar. The development of

Michael Strotkamp

michael.strotkamp@ilt.fraunhofer.de

1 Fraunhofer Institute for Laser Technology ILT, Steinbachstr. 15, 52074 Aachen, Germany

2 Leibniz Institute of Atmospheric Physics, Schlossstraße 6, 18225 Kühlungsborn, Germany a spaceborne resonance lidar instrument is deferred by the lack of laser sources at the demanded wavelengths that are suitable for spaceborne operation.

The currently used Alexandrite $\left(\mathrm{Cr}^{3+}: \mathrm{BeAl}_{2} \mathrm{O}_{4}\right)$ lasers with their broad tunability $(700-800 \mathrm{~nm})$ [13] are well suited for the generation of several interesting wavelengths, either operating at their fundamental wavelength or intra-cavity frequency doubled. The flashlamp-pumped Alexandrite ring lasers operating in Q-switched single-longitudinal-mode (SLM) operation are commonly used as beam sources in resonance potassium and iron resonance lidar systems [6-9].

However, the usage of flashlamps as pump source makes them unsuitable for spaceborne operation, due to the poor efficiency and limited lifetime. One hopeful approach to overcome these drawbacks is by replacing the flashlamps with diode lasers $[14,15]$. Recently, new basic investigations in the field of diode-pumped Alexandrite lasers have been conducted with focus on altimetry lidar and vegetation monitoring (red edge) [16] and resonance lidar [17-21].

Another approach to address a resonance line of iron with a lidar system is the usage of a Nd:YAG laser operating at $372 \mathrm{~nm}$ (third harmonic of $1116 \mathrm{~nm}$ ) [9]. The advantage is the usage of well-matured technology for Nd:YAG lasers but at the expense of a two-step nonlinear process. 
To address the resonance line of sodium a $589 \mathrm{~nm}$, there are two approaches already aiming for a spaceborne mission by allowing leverage from previous space-qualified lasers. The first system uses the second harmonic of a Ramanshifted $\mathrm{Nd}: \mathrm{YVO}_{4}$ laser [11], and the second system is mixing the output of two Nd:YAG lasers: one emitting at $1064 \mathrm{~nm}$ and one at $1319 \mathrm{~nm}[12]$.

\section{Requirements and state of the art}

The requirements to the laser source can be directly derived from the application in a resonance lidar; especially, the spectral requirements are challenging because the metal resonance line is scanned to calculate its width and shift. This requires a linewidth of the laser below $30 \mathrm{MHz}$ and consequently a laser with SLM operation.

The energetic requirements strongly depend on the specific metal line and the targeted resolution of the measurement, but an average power at the watt level with pulse energies at the millijoule level seems reasonable for our detection method based on single photon counting. Since the average power determinates finally the performance of a lidar, high pulse energies are often not required and may limit the capability of a lidar in single photon counting mode due to detector saturation. Here, high pulse energies are required with low repetition flashlamp-pumped lasers to achieve high average power. In contrast, diode-pumped lasers observing a limited altitude range such as the mesosphere can apply high repetition rates with lower pulse energy. For detailed discussion on the energetic requirements, see Sect. 6.

For a proof of principle, a diode-pumped Alexandrite laser for a ground-based lidar measurement of potassium in the upper atmosphere (MLT $\sim 80-100 \mathrm{~km}$ ) is designed that has the same spectral but slightly eased energetic requirements shown in Table 1. A spaceborne laser can, if necessary, be scaled in energy by means of a subsequent amplifier stage without altering its spectral or temporal parameters.

A first developed Alexandrite laser comprises a ring resonator pumped by two commercially available laser diode modules. The ring resonator ensures a traveling wave to prevent spatial hole burning, and its resonator length is stabilized to match it to a narrow band diode laser. It also comprises a Faraday rotator for unidirectional operation and a Pockels cell for Q-switching to ensure suitable pulse durations. A detailed description of the design and performance data of the laser source can be found in [17].

After verification of the required laser parameters in the laboratory at the Fraunhofer ILT in Aachen, the laser was implemented in a mobile lidar system at the Leibniz IAP in Kühlungsborn. The first atmospheric measurements with a diode-pumped Alexandrite laser as the beam source of a lidar system were successfully conducted. Despite
Table 1 Requirements on a laser source for potassium resonance lidar measurements in the upper atmosphere

\begin{tabular}{ll}
\hline Parameter & Requirement \\
\hline Pulse energy & $>1 \mathrm{~mJ}$ \\
Repetition rate & $>150 \mathrm{~Hz}$ \\
Electro-optical efficiency & $>1 \%$ \\
Pulse duration & $50-1000 \mathrm{~ns}$ \\
Wavelength & $769.898 \mathrm{~nm}$ \\
& (potassium \\
& resonance line \\
& in air) \\
Linewidth & $\sim 99 \%<30 \mathrm{MHz}$, \\
& single-mode \\
& $($ lorentz) \\
Frequency shift & $<50 \mathrm{MHz}$ \\
Frequency jitter & $<10 \mathrm{MHz}$ \\
Beam quality & $M^{2}<1.5$ \\
Pointing stability & $<10 \mu \mathrm{rad}$ \\
\hline
\end{tabular}

the tentative setup of the receiver of the lidar system, the detected light indicates the potassium layer at an altitude of $80-100 \mathrm{~km}$, proving the suitability of the laser source. Detailed information on these measurements and the lidar system is presented in [19] and will be published in more detail soon. Up to now, the spectral and energetic suitability of the laser was demonstrated in hundreds of operating hours.

The successful lidar measurements demonstrate that a diode-pumped Alexandrite laser can meet the high spectral requirements of a resonance lidar. Thus, after the demonstration of a ground-based resonance lidar measurement, the development of a spaceborne resonance lidar system with a diode-pumped Alexandrite is plausible. Consequently, a more sophisticated laser beam source and setup of the receiver of the lidar system are required.

\section{Design of a compact and robust laser source}

After the proof of principle that resonance lidar measurements can be conducted with diode-pumped Alexandrite lasers shown in [17], an advanced Alexandrite laser is developed with higher energetic parameters and a less complex and therefore more robust resonator design. Special emphasis is put on the pump optics, since the unbalanced beam quality of the diode modules $\left(M^{2}=30\right.$ in fast-axis and $M^{2}=300$ in slow-axis) leads to a highly anamorphic thermal lens which results in a complex design of the resonator. A detailed characterization of the pump modules and the influence on the resonator can be found in [17]. 


\subsection{Pump optics}

To overcome these drawbacks, the two pump modules are polarization coupled and symmetrized by means of step mirrors [22] to balance the beam qualities and provide a round pump beam cross section. A detailed description of the optical setup can be found in [20]. The optics design and optomechanical setup are based on off-the-shelf components and have not yet been optimized for compactness or transmission efficiency.

To allow for further homogenization of the pump beam and for spatially separating the pump and the resonator unit, fiber coupling of the pump radiation is preferable [21]. Thus, the resonator can be developed independent from the pump. The complete pump setup is shown in Fig. 1.

Because the absorption of pump light is a magnitude lower for light at $636 \mathrm{~nm}$ vertically polarized to the b-axis of the crystal [13], $40 \%$ of the unpolarized pump light is not absorbed at its single pass through the laser crystal, which has a dopant concentration of 0.29 at $\%$. The transmitted pump light is collimated behind a second pumping mirror, reduced in its size by a telescope, its polarization adjusted by double passing a quarter-wave plate and refocused into the crystal. The backfolded light is absorbed on its way back through the crystal and guarantees a homogenously pumped crystal. A similar approach is presented in [20] and [21].

\subsection{Laser design}

Since the resonator design presented in [20] yielded good experimental results, the design is unchanged for the resonator in this publication, with the exception of the separation of the pump and resonator unit due to the fiber-coupled pump device. The laser resonator is schematically shown in Fig. 2. It is built on a breadboard with commercial optomechanics without special emphasis on compactness or thermomechanical stability. It comprises one Alexandrite crystal with an aperture of $2 \times 2 \mathrm{~mm}^{2}$ and a length of $7 \mathrm{~mm}$ that is operated at a temperature of $105{ }^{\circ} \mathrm{C}$. The resonator has a total length of approximately $2000 \mathrm{~mm}$ and comprises one Alexandrite crystal mounted in an oven to control the temperature of the crystal, two dichroic pumping mirrors with high transmission for the pump wavelength, several plane folding mirrors and two curved mirrors with high reflectivity for the laser wavelength, a Brewster-angled Pockels cell and two thin-film polarizers (TFP) to allow Q-switching, two half-wave plates for polarization adjustment, a Faraday rotator for unidirectional operation and a plane output coupler with $3 \%$ transmission for the laser wavelength. The two concave mirrors have a radius of curvature of $-900 \mathrm{~mm}$, and both pumping mirrors are plane.

The resonator is designed for a laser beam radius of around $200 \mu \mathrm{m}$ in the crystal which results in a good overlap with the pump beam. The beam radius on the critical optical components like the Pockels cell or the Faraday rotator is around $700 \mu \mathrm{m}$, preventing laser-induced damage.

SLM operation of the Alexandrite laser is achieved by seeding the resonator with a commercial external cavity diode seed laser that operates at the desired wavelength in $\mathrm{cw}$ operation. The linewidth of the seed laser is $<1 \mathrm{MHz}$, and the output power is about $20 \mathrm{~mW}$. To achieve SLM operation, the seed laser is spatially matched with the resonator mode and the cavity length is matched to the desired wavelength by one of the plane resonator mirrors

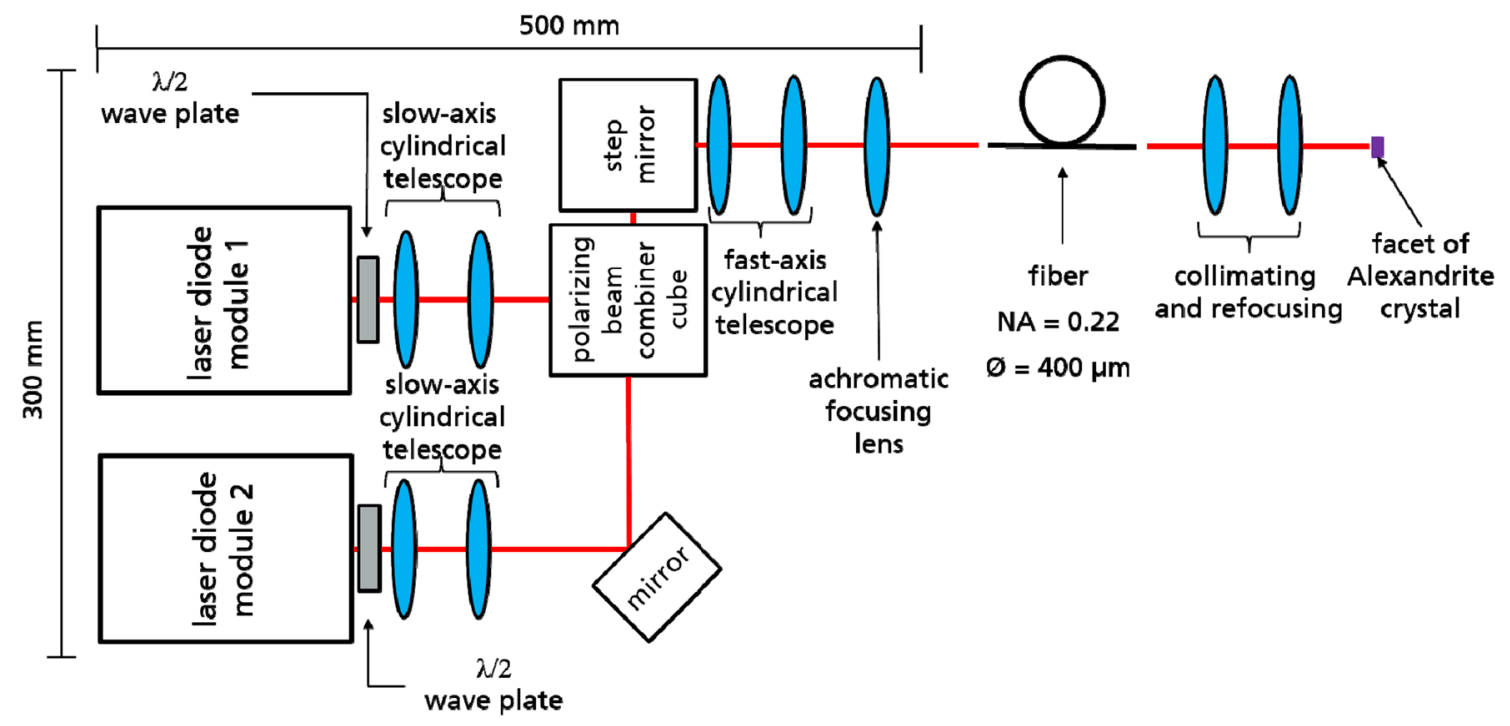

Fig. 1 Schematic drawing of the pump setup including the collimation and refocusing of the pump radiation after the fiber 
Fig. 2 Schematic drawing of the resonator including the backfolding of the transmitted pump light

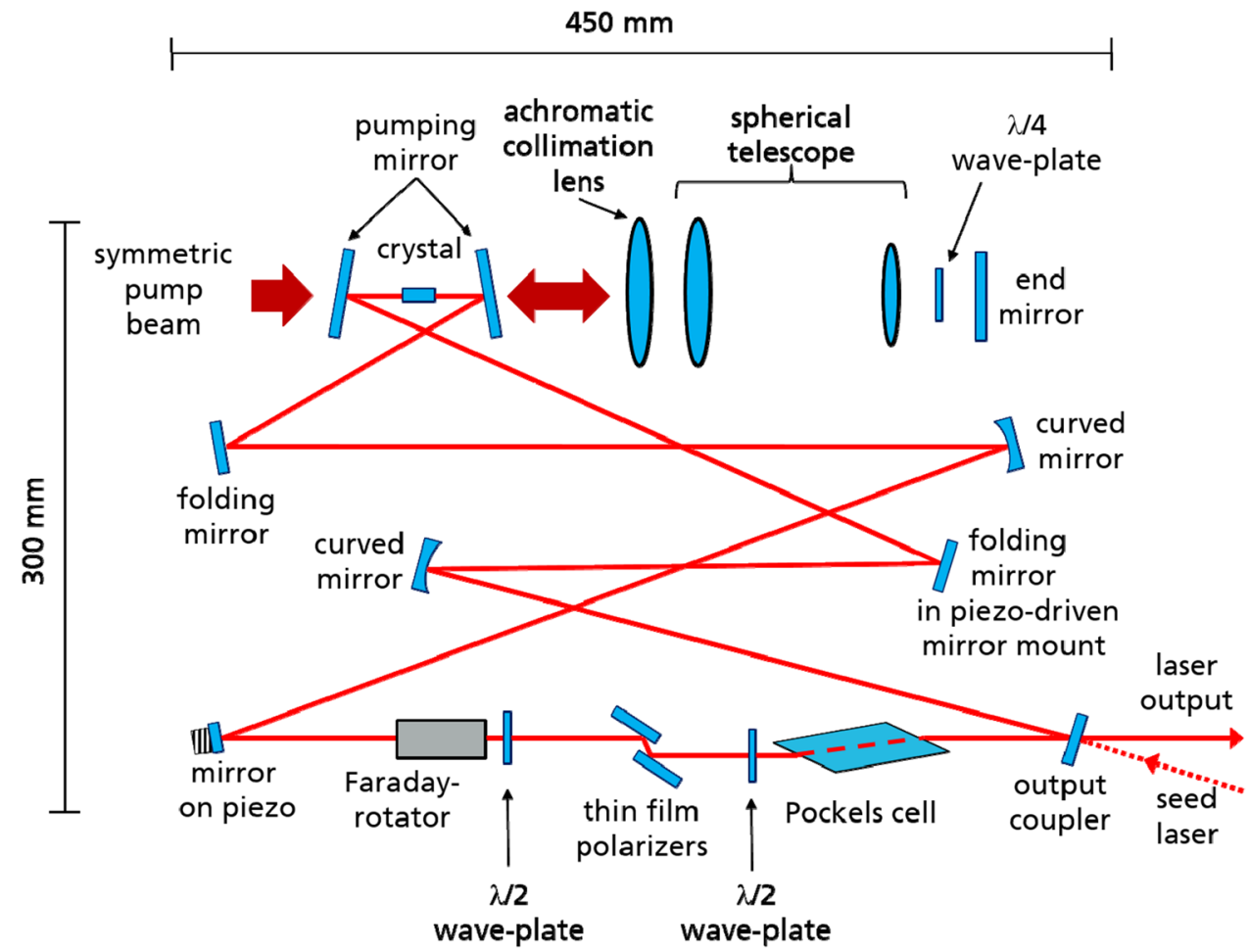

mounted on a piezo-actuator. Stabilized SLM operation can be achieved with seeding power $\ll 1 \mathrm{~mW}$ using the ramp-and-fire method described in [23].

\section{Experimental results}

The first symmetrization of the pump radiation results in a beam quality of $M^{2}=100$ in fast- and $M^{2}=150$ in slowaxis. The pump radiation is focused with an achromatic lens with a focal length of $f=75 \mathrm{~mm}$, resulting in focus radii of $w=150 \mu \mathrm{m}$ in fast- and $w=190 \mu \mathrm{m}$ in slow-axis. The combined pulse energy behind all pump optics is $24 \mathrm{~mJ}$ with a pump pulse duration of $120 \mu$ s. Fiber coupling into an uncoated optical fiber with a numerical aperture of $\mathrm{NA}=0.22$ and a core diameter of $\varnothing=400 \mu \mathrm{m}$ yields coupling losses of $25 \%$. Consequently, the pulse energy deposited in the laser crystal is $18 \mathrm{~mJ}$. The beam quality after the fiber is $M^{2}=200$ in both directions. A caustic of the pump radiation with a beam profile is shown in Fig. 3. The focus radius in the crystal is $w=280 \mu \mathrm{m}$ in both spatial directions.

In Q-switched operation, the laser yields a pulse energy of $1.73 \mathrm{~mJ}$ and features a high pulse-to-pulse stability of $0.2 \%$ (rms) at a repetition rate of $500 \mathrm{~Hz}$, resulting in an average power of $0.85 \mathrm{~W}$ with a pulse duration of $850 \mathrm{~ns}$. A measurement of the pulse energy over time is plotted in Fig. 4a. It is noticeable that the pulse energy of the laser is slightly higher than the energy measured in [20], although the pump energy deposited into the crystal is $25 \%$ lower. The resulting

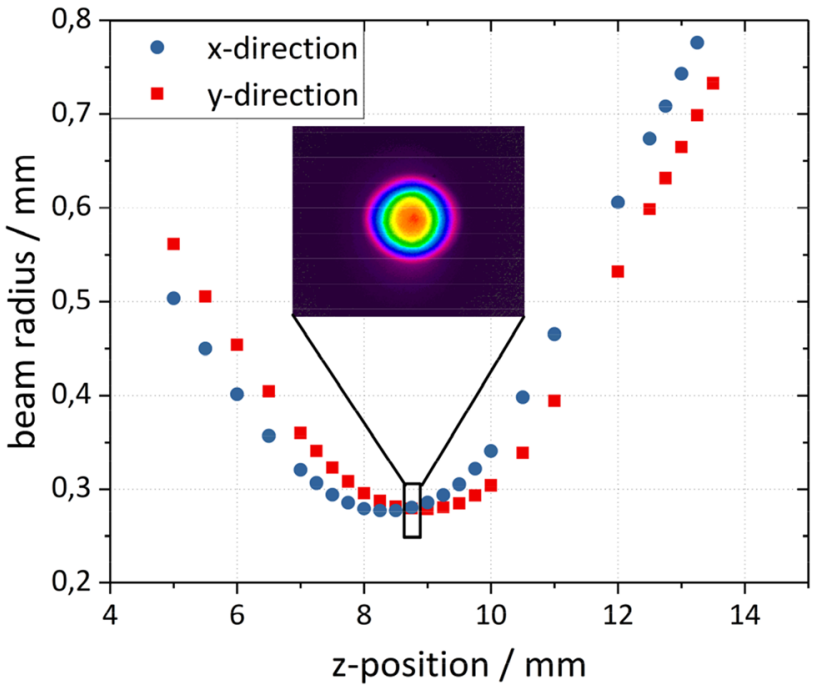

Fig. 3 Caustic of the pump beam after the fiber

optical-optical efficiency of the laser with the fiber-coupled pump device is $9.7 \%$ and thus $30 \%$ higher than without fiber coupling of the pump radiation. The main reason for these results is the further homogenization of the pump beam leading to a round pump spot along the whole propagation through the crystal [21]. Thus, the results presented in this publication demonstrate not only the feasibility of efficient fiber coupling of the red pump modules but also the benefits of a fiber-coupled pump module for the oscillator. 


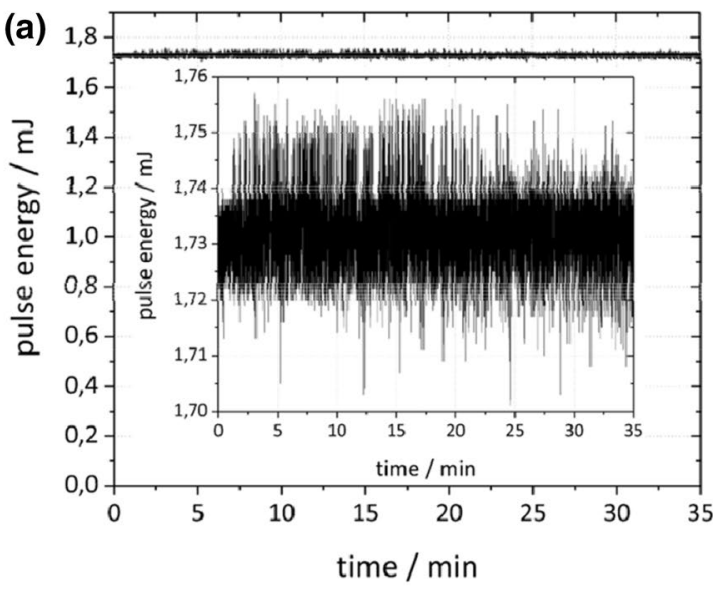

Fig. 4 a Measured pulse energy in Q-switched operation over more than 30 min with a zoom on the relevant energy regime as inlet and $\mathbf{b}$ beam radius of output beam plotted against propagation length with

Taking into account the electro-optical efficiency of the diode modules of $33 \%$ and the transmission losses of the pump optics of approximately $20 \%$ as well as the coupling efficiency of $75 \%$, the laser features an electro-optical efficiency of $2 \%$.

The output beam is round and stigmatic so that no additional cylindrical beam shaping is necessary. The beam profile of the laser has a Gaussian shape with a beam quality of $M^{2} \leq 1.1$ in both spatial directions. A caustic of the output beam with beam profiles at selected positions of the optical axes is plotted in Fig. 4b.

Seeding the laser and stabilizing the cavity length result in a slight loss of pulse energy of 5\% while the spatial and temporal parameters of the Alexandrite laser are unchanged compared to the unseeded laser. The linewidth is measured with a spectrum analyzer developed at the IAP in Kühlungsborn. Comparison with the measured linewidth of the seed laser and the laser published in [17] indicates a linewidth $<10 \mathrm{MHz}$

The laser's average power is more than five times higher with a pulse energy stability one magnitude higher, and the electro-optical efficiency is doubled compared to [17]. Additionally due to the symmetric pump beam and careful laser design, the laser is easier to align and less sensitive against changes of the thermal lens or misalignment compared to its predecessor. The requirements set by the application are fulfilled as shown in Table 2.

\section{Suitability for spaceborne application}

For spaceborne operation of the laser system, the optical elements have to be qualified regarding operation in low earth orbit. However, no publications on radiation testing were

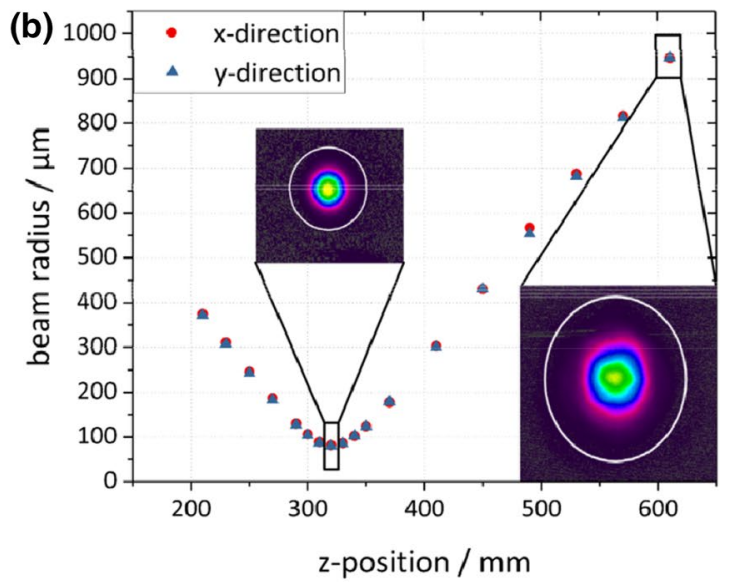

inset of intensity profile at designated positions. The resulting beam qualities are $M^{2}=1.09$ in x-direction and $M^{2}=1.06$ in y-direction

Table 2 Requirements and achieved parameters

\begin{tabular}{lll}
\hline Parameter & Requirement & Achieved \\
\hline Pulse energy & $>1 \mathrm{~mJ}$ & $1.73 \mathrm{~mJ}$ \\
Repetition rate & $>150 \mathrm{~Hz}$ & $500 \mathrm{~Hz}$ \\
Electro-optical efficiency & $>1 \%$ & $2 \%$ \\
Pulse duration & $50-1000 \mathrm{~ns}$ & $850 \mathrm{~ns}$ \\
Wavelength & $769.898 \mathrm{~nm}$ (potas- & $769.898 \mathrm{~nm}$ \\
& sium resonance line & \\
& in air) & \\
Linewidth & $<30 \mathrm{MHz}(\sim 99 \%)$, & $<10 \mathrm{MHz}^{*}$ \\
& single-mode (lor- & \\
Frequency shift & entz) & $<10 \mathrm{MHz}^{*}$ \\
Frequency jitter & $<50 \mathrm{MHz}$ & $<1 \mathrm{MHz}^{*}$ \\
Beam quality & $<10 \mathrm{MHz}$ & $M^{2}<1.1$ \\
Pointing stability & $M^{2}<1.5$ & $<3 \mu \mathrm{rad}$ \\
\hline
\end{tabular}

Values with $*$ are preliminary values based on the values measured in [17]

found for the pump diode emitter material and the Alexandrite crystal, so space qualification of the pump diodes and the laser medium is still pending. Changing the Pockels cell crystal from $\mathrm{KD}^{*} \mathrm{P}$ to $\mathrm{BBO}$, which has already been space qualified, should be possible since $\mathrm{BBO}$ was already used in Q-switched Alexandrite lasers before [16]. The TGG crystal used for the Faraday rotator is also already qualified for space operation.

For the evaluation of the laser design regarding stability under space condition, a performance analysis is carried out. The susceptibility to misalignment is compared with the performance of the mounting technology, developed at the Fraunhofer ILT and demonstrated in "FULAS (Future Laser System) platform" [24] and the laser for MERLIN, 
a French-German space lidar mission dedicated to atmospheric methane [25]. Thereby, the remaining effort to achieve space qualification of the laser concept is estimated.

\subsection{Optomechanical components for spaceborne lasers at ILT}

In particular, spaceborne laser systems require compact, robust and outgassing free key components in order to achieve maintenance free or low-maintenance operation over several years in rough environment. The soldering technique that has been developed for the mounting of diode laser bars as well as solid-state laser crystals has been transferred to different laser optical key components. A selection of them is shown in Fig. 5 and described in [26] which are mirror and lens mounts as well as Pockels cell packages and Faraday isolators. All of them are complete free from organic material and have been environmentally tested. All of these components were designed to meet the strong requirements for spaceborne laser systems; especially, the mirror mounts meet the extremely high stability requirements against tilting, being $<10 \mu \mathrm{rad}$, during the whole operational and after the non-operational temperature range and non-operational random vibration spectra.

For the FULAS project (see [24]), a complete laser is integrated based on these components. This laser comprises a single-longitudinal-mode oscillator and one InnoSlab amplifier stage [27] and successfully completed a multi-week operational $\left(+10\right.$ to $\left.+30{ }^{\circ} \mathrm{C}\right)$ and non-operational $\left(-30\right.$ to $\left.+50{ }^{\circ} \mathrm{C}\right)$ test in a thermal vacuum chamber at Airbus Defense and Space.

The diode-pumped Alexandrite laser presented here comprises, besides the mirrors, a Faraday rotator and a Pockels cell whose requirements are fulfilled by the components developed at the ILT for spaceborne operation.

\subsection{Measurement of the susceptibility to misalignments}

Regarding the stability against tilting, the mirrors of the resonator are by far the hardest to fulfill specification. Therefore, the susceptibility of the Alexandrite laser to misalignments of folding mirrors in the resonator is measured. The off-the-shelves optomechanical mounts used for the resonator setup cannot fulfill the requirements, but in the relatively stable environment of the laboratory the susceptibility of the design can be investigated. One of the plane folding mirrors is mounted in a piezo-driven mirror mount (as shown in Fig. 2) that has a resolution of $\sim 0.5 \mu \mathrm{rad}$ for a $0.1 \mathrm{~V}$-step.

The mirror is tilted in pitch and yaw separately while the other spatial direction remains unchanged and therefore well aligned. For each tilting step, the pulse energy, beam quality and linewidth of the seeded and stabilized laser are measured. The results are shown in Fig. 6 for both pitch and yaw.

For a tilting of $\pm 125 \mu \mathrm{ad}$ and $\pm 140 \mu \mathrm{ad}$ in pitch and yaw, respectively, the pulse energy drops by $10 \%$ while
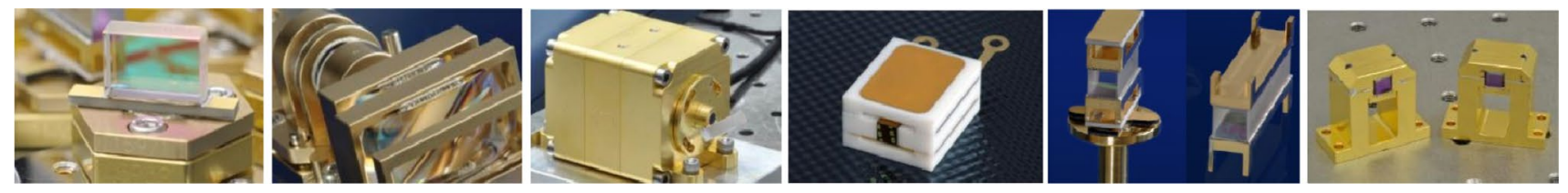

Fig. 5 Examples of optomechanical components developed for spaceborne lasers. From left: pick and align mirror mount, reflow-soldered pump optics, Faraday isolator, Pockels cell, NLO crystals and laser crystals
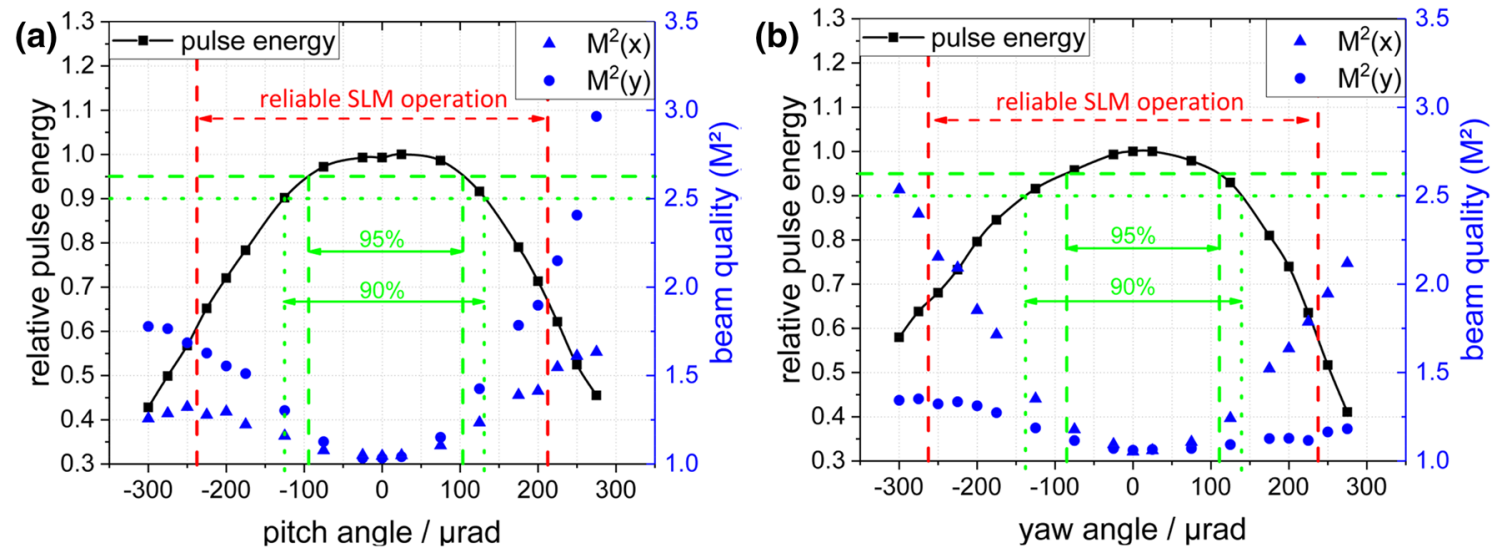

Fig. 6 Pulse energy and beam quality of the seeded and stabilized laser for $\mathbf{a}$ pitch and $\mathbf{b}$ yaw tilting 
the beam quality in both directions $\left(M^{2}<1.3\right)$ is still meeting the requirements. Even for a tighter limit of 5\% energy drop, a tilting of $\pm 100 \mu$ ad both in pitch and yaw is tolerable. The SLM operation is also reliable over a broad tilting $(> \pm 200 \mu \mathrm{ad})$ in both directions.

The results for the folding mirror that is tilted are not representative for the other optics. An analytical analysis based on a $3 \times 3$ beam matrix formalism for misaligned optical elements, as described, e.g., in [28], allows a conversion of the results to every position within the resonator.

The tolerance analysis of the laser system is conducted analytically, assuming Gaussian beams and a paraxial optical system. Similar attempts have been carried out for simple resonator geometries $[29,30]$ and for arbitrary resonators [31], but only taking into account the displacement and tilt of the mode. However, the resulting reduction in output power was not described in these papers.

Details on the theoretical basis of the tolerance analysis can be found in [18]. The results of this analysis verify the results from the measurement of the susceptibility to misalignment. A tilting of the mirror in the piezo-driven mount of $1 \mathrm{mrad}$ results in a displacement of the laser mode in the laser crystal of $0.28 \mathrm{~mm}$. The $100 \mu \mathrm{rad}$ tilting for with the measurement shows a reduction of $5 \%$ of the pulse energy (Fig. 6) correlates with a displacement of $28 \mu \mathrm{m}$. This corresponds to a displacement of about $10 \%$ of the pump beam radius, and the only slightly reduced overlap of laser mode and pumped crystal volume makes the energy reduction plausible.

The highest susceptibility to misalignment shows the mirrors between the two curved mirrors, e.g., the output coupler and the mirror mounted on the piezo-actor for stabilization of the cavity length. For those mirrors, the displacement of the laser modes is twice as large compared with the mirror in the piezo-driven mount. Therefore, the tilting that is acceptable for a pulse energy reduction of $5 \%$ is still $\pm 50 \mu \mathrm{rad}$, and therefore, the mirror mounts developed at ILT should be suitable for setting up an Alexandrite laser for spaceborne operation.

Beside the tentative mechanical setup and the non-optimized folding for a small footprint, the results indicate that the mirror mounts developed at ILT for spaceborne lasers with tilting $<10 \mu \mathrm{rad}$ will suffice to set up the resonator.

\section{A possible future mesospheric space mission}

As an example for a possible future space mission, the focus is on the mesosphere. Compared to iron and sodium, a potassium Doppler lidar is straightforward without the complex laser technology needed for nowadays sodium lidar [10-12]. Iron still has the disadvantage of additional SHG and fast degrading of optics due to a UV wavelength. Both Fe and $\mathrm{Na}$ require finally SHG of the pulsed laser. A general disadvantage of $\mathrm{Na}$ and $\mathrm{Fe}$ is therefore also the lack of a reference at the seeder wavelength. Potassium is an elegant and highly efficient alternative, avoiding complex optical setups with a laser system operating close to maximum gain at the required wavelength. As frequency reference, potassium saturation spectroscopy is straightforward, similar to the well-known rubidium saturation spectroscopy. However, rubidium saturation spectroscopy or a Faraday filter is also a possible solution, as described in [19].

A realistic estimation of the signal strength from space can be derived by extrapolating ground-based observations of the former mobile potassium lidar of the IAP [7]. This resonance lidar system uses flashlamp-pumped Alexandrite ring lasers as beam source and has been operated for more than two decades. So far, this system is worldwide the only transportable resonance lidar for mesospheric Doppler measurements. Doppler temperature measurements in 1996 at the potassium line on board of the ice breaker "MS Polarstern" in Antarctica [7] show that high-resolution Doppler temperature measurements with less than 1-MHz spectral resolution are achieved on a strongly vibrating and moving platform by controlling the cavity length of the ring laser with the rampand-fire technology.

For comparison, Fig. 7 shows on the left side a potassium measurement with the diode-pumped Alexandrite laser presented in [17], operating at $\sim 0.15 \mathrm{~W}$ in a preliminary, not optimized optical setup. With a $60-\mathrm{cm}$ telescope and a Faraday filter, the setup is similar to the former potassium lidar, except that we observed only half of the resonance signal at one polarization. The laser was operating for $47 \mathrm{~min}$ at the center frequency of the atomic line. The right side shows the signal of a Doppler temperature measurement at Spitsbergen, $78^{\circ} \mathrm{N}$ in 2001 , with the flashlamp-pumped ring laser operating at approx. $4 \mathrm{~W}$ with $80-\mathrm{cm}$ telescope and Double Faraday filter [32]. For Doppler measurements, the frequency is tuned from pulse to pulse about the atomic line. The shown integrated resonance signal represents therefore a reduced average signal about all frequencies for $102 \mathrm{~s}$.

With this setup, first Doppler temperature measurements within summer time at a polar region show exceptional low temperatures in summer [33] and mesospheric clouds (NLC), observable roughly $70 \%$ of the time. The signal of the strong NLC in this example is 80 photons $/ \mathrm{s} / 200 \mathrm{~m}$ and therefore sufficient to detect such an ice cloud in less than $1 \mathrm{~s}$ in the mesosphere. The signal from the potassium layer is lower and suffers from strong saturation due to the small field of view required for daylight observations from ground. Still, 10 photons/s/200 m are obtained, even though scanning the atomic line results in a reduced signal. Because of the high pulse energies of the flashlamp-pumped lasers, any signal below about $45 \mathrm{~km}$ altitude cannot be measure due 

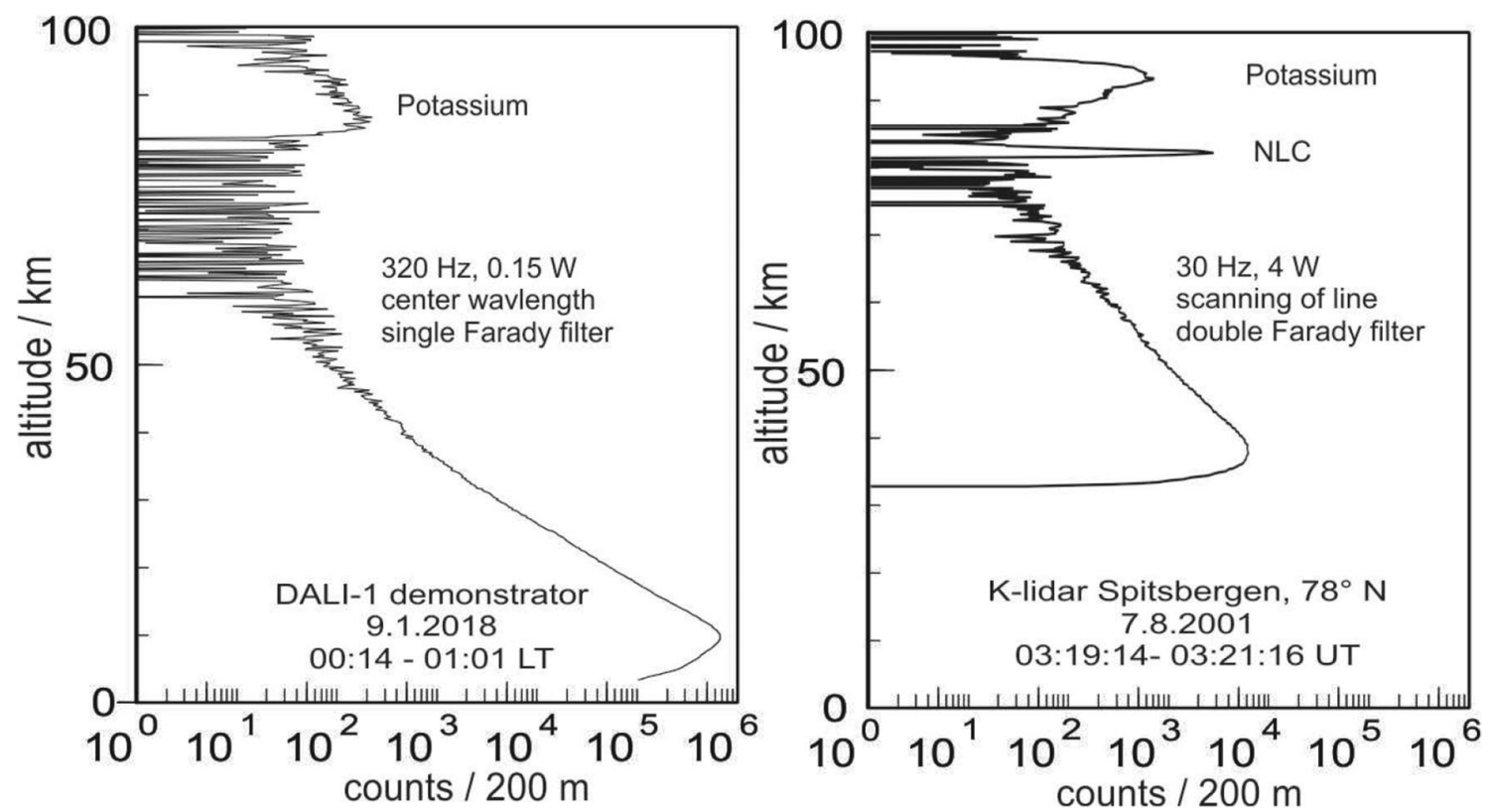

Fig. 7 Left side: demonstration of a mesospheric measurement with the laser described in [17]. Right side: potassium layer and NLC at daytime in 2001 with a flashlamp-pumped Alexandrite ring laser, scanning the atomic line for Doppler temperatures

to detector saturation. These illustrates that high pulse energies are a disadvantage since the lower atmosphere cannot be observed simultaneously and the signal from the mesosphere can exceed the maximum possible count rate in single photon counting mode. Moreover, the field of view cannot be reduced further because of the limits given by resonance scattering. High pulse energies limit therefore the dynamic range of the detector at daytime due to the unavoidable high solar background. A mechanical chopper avoids nonlinear response of the signal at higher altitudes by blocking the signal below about $45 \mathrm{~km}$ altitude.

The comparison in Fig. 7 shows that even with the unsophisticated laser beam source described in [17] and a tentative lidar system, mesospheric measurements are already feasible. Improvements in the lidar electronics and the telescope alignment should yield an increase in signal strength of a factor 2-3. In combination with the five times higher laser power of the diode-pumped Alexandrite laser presented in this publication, the signal strength can be scaled by a magnitude. Therefore, a lidar system with a diode-pumped Alexandrite laser as the beam source that is comparable to the time-tested potassium lidar of the IAP based on flashlamp-pumped Alexandrite lasers is plausible.

The orbit for such a mission strongly depends on the specific scientific question to be addressed, but for an assessment an altitude similar to the active lidar missions AEOLUS (wind, $320 \mathrm{~km}$ ) or MERLIN (methane, $500 \mathrm{~km}$ ) is assumed, From space, a three times larger signal from potassium avoiding saturation is measured. The transmission through the lower atmosphere for ground-based observations at clear sky is $\sim 0.78$. From space, the resonance line at $766 \mathrm{~nm}$ is accessible with approx. twice the backscatter coefficient. By replacing the 20-year-old optics with a better interference filter, polarizers and a high transmission Faraday filter, the signal gain can be increased by a factor 1.5. With these improvements alone, the signal from the potassium layer increases altogether by more than one magnitude. Since the distance from ground is $\sim 90 \mathrm{~km}$, the potassium signal shown in Fig. 7 on the right side can be expected for a satellite with similar parameters at three to four times larger distance or roughly $400 \mathrm{~km}$ altitude. At such a distance, the NLC is still detectable with $\sim$ six times reduced signal within a second. The overall capability for Rayleigh, Mie and resonance measurements is finally given by the field of view of the system, spectral filtering (for reducing the solar background) and orbit parameters and can therefore only be calculated more accurate for a given space mission and laser parameter. Depending on the required laser performance, an Alexandrite laser as described in this publication may achieve already all requirements without even additional energy scaling by an amplification stage and therefore increased complexity. Otherwise, the FULAS platform involves a technology for energy scaling based on InnoSlab amplifier that can be adapted to diode-pumped Alexandrite.

From space, potassium benefits significant from the larger distance avoiding saturation of ground-based lidar and additionally by shifting the wavelength $3 \mathrm{~nm}$, observing the stronger resonance line at $766 \mathrm{~nm}$. Ground-based measurements of iron at $386 \mathrm{~nm}$ are also possible by operating the laser at $772 \mathrm{~nm}$ with additional SHG or by operating the 
ring laser at $744 \mathrm{~nm}$ observing the $372 \mathrm{~nm}$ line. A SHG with a conversion efficiency of $61 \%$ for generating $386 \mathrm{~nm}$ was demonstrated with a flashlamp-pumped Alexandrite ring laser [34]. From ground, Fe suffers from strong absorption in the troposphere with a two-way transmission in the order of approx. 0.3-0.35. The signal of a spaceborne Fe lidar is therefore approximately three times stronger compared to a ground-based Fe lidar. The stronger backscatter coefficient of the 372-nm resonance line is partly compensated by choosing circular polarization. Circular polarization increases the backscatter coefficient due to the Hanle effect by $18 \%$ compared to $6 \%$ for the $372-\mathrm{nm}$ resonance line. Moreover, circular polarization simplifies the data analysis since the backscatter coefficient for resonance scattering depends otherwise strongly on the magnetic field and the orientation of the instrument relative to the magnetic field vector.

Whereas $372 \mathrm{~nm}$ has been used in the past for observing the Fe layer from Antarctic to Europe on a ship borne campaign in 1990 [35], a Doppler temperature Fe lidar based on a flashlamp-pumped Alexandrite ring laser at $386 \mathrm{~nm}$ has recently discovered the elevated mesopause in Antarctica [36]. Whereas a slightly larger signal is achieved at $372 \mathrm{~nm}$, a wavelength shift of only $2 \mathrm{~nm}$ is required for observing $\mathrm{Fe}$ and $\mathrm{K}$ simultaneously with a slightly more complex setup by changing the wavelength from pulse to pulse with a second seeder laser. In future, more advanced lidar systems based on Alexandrite may therefore observe multiple metals with a single laser system from space. Since the technology of the IAP does not depend on a reference at the measured wavelength, multiple wavelength Doppler measurements are principle in reach with a single reference on one of the measured wavelengths. Extending a potassium lidar with saturation spectroscopy is therefore straight forward by adding a second seeder, additional SHG of the Alexandrite and separate receiver for the UV wavelength. Alternative rubidium saturation spectroscopy might be used for an iron lidar without observing potassium. As an example for other applications, we note that SHG or the less known stimulated Raman emission toward the longer wavelength range allows, e.g., a metastable Helium lidar [37] for the thermosphere $\left(389 \mathrm{~nm}\right.$ or $1083 \mathrm{~nm}$ ) or observing $\mathrm{Ca}^{+}$at $393 \mathrm{~nm}$.

\section{Summary}

In this work, an Alexandrite ring laser in Q-switched single-longitudinal-mode operation pumped by a fiber-coupled diode laser is presented.

The self-developed fiber-coupled laser diode pump device yields a pump energy of $18 \mathrm{~mJ}$ with a beam quality of $M^{2}=200$ in both spatial directions. The fiber-coupled pump unit yields a homogenous and stigmatic pump beam that allows for a less complex resonator design with high energetic stability. The laser yields a pulse energy of $1.73 \mathrm{~mJ}$ with an excellent beam quality $M^{2}<1.1$ in both directions. The electro-optical efficiency of $2 \%$ is the highest achieved for all Alexandrite lasers in SLM operation and reasonable for spaceborne operation.

The spectral and energetic suitability of the laser is demonstrated by an analysis of atmospheric measurements conducted with a diode-pumped Alexandrite laser presented in a former publication of our group.

A performance analysis as well as benchmarking with the space-qualified mounting technology points out the TRL and the remaining effort of development of the technology.

The comparison of the atmospheric measurements with flashlamp- and diode-pumped Alexandrite lasers and a consideration of the changing lidar parameters for a spaceborne observation of the mesosphere underline the feasibility of a combined $\mathrm{K}$ and $\mathrm{Fe}$ lidar with a diode-pumped Alexandrite laser as the beam source for a spaceborne lidar mission.

Acknowledgements The work is funded by the German Aerospace Center (DLR) as a representative for the Federal Ministry for Economic Affairs and Energy (BMWi) (FKZ 50RP1605).

Open Access This article is distributed under the terms of the Creative Commons Attribution 4.0 International License (http://creativeco mmons.org/licenses/by/4.0/), which permits unrestricted use, distribution, and reproduction in any medium, provided you give appropriate credit to the original author(s) and the source, provide a link to the Creative Commons license, and indicate if changes were made.

\section{References}

1. Kaifler, B., Lübken, F.-J., Höffner, J., Morris, R.J., Viehl, T.P.: Lidar observations of gravity wave activity in the middle atmosphere over Davis $\left(69^{\circ} \mathrm{S}, 78^{\circ} \mathrm{E}\right)$, Antarctica. J. Geophys. Res. Atmos. 120, 4506-4521 (2015)

2. Lübken, F.-J., Höffner, J., Viehl, T.P., Becker, E., Latteck, R., Kaifler, B., Murphy, D., Morris, R.J.: Winter/summer transition in the Antarctic mesopause region. J. Geophys. Res. Atmos. 120, 394-409 (2015)

3. Zhao, J., Chu, X., Chen, C., Lu, X., Fong, W., Yu, Z., Jones, R.M., Roberts, B.R., Dörnbrack, A.: Lidar observations of stratospheric gravity waves from 2011 to 2015 at McMurdo $\left(77.84^{\circ} \mathrm{S}\right.$, $\left.166.69^{\circ} \mathrm{E}\right)$, Antarctica: 1. Vertical wavelengths, periods, and frequency and vertical wave number spectra. J. Geophys. Res. Atmos. 122(10), 5041-5062 (2017)

4. Lübken, F.-J., Höffner, J., Viehl, T.P., Kaifler, B., Morris, R.J.: First measurements of thermal tides in the summer mesopause region at Antarctic latitudes. Geophys. Res. Lett. 38, L24806 (2011). https://doi.org/10.1029/2011GL050045

5. Rapp, M., Lübken, F.-J., Müllemann, A., Thomas, G.E., Jensen, E.J.: Small scale temperature variations in the vicinity of NLC: experimental and model results. J. Geophys. Res. 107(D19), AAc11 (2002). https://doi.org/10.1029/2001JD001241

6. Höffner, J., Lübken, F.-J.: Potassium lidar temperatures and densities in the mesopause region at Spitsbergen $\left(78^{\circ} \mathrm{N}\right)$. J. Geophys. Res. 112, D20114 (2007) 
7. von Zahn, U., Höffner, J.: Mesopause temperature profiling by potassium lidar. Geophys. Res. Lett. 23, 141-144 (1996)

8. Lautenbach, J., Höffner, J.: Scanning iron temperature lidar for mesopause temperature observation. Appl. Opt. 43(23), 45594563 (2004)

9. Kaifler, B., Büdenbender, C., Mahnke, P., Damm, M., Sauder, D., Kaifler, N., Rapp, M.: Demonstration of an iron fluorescence lidar operating at $372 \mathrm{~nm}$ wavelength using a newly-developed Nd:YAG laser. Opt. Lett. 42, 2858-2861 (2017)

10. Kawahara, T.D., Nozawa, S., Saito, N., Kawabata, T., Tsuda, T.T., Wada, S.: Sodium temperature/wind lidar based on laser-diodepumped Nd:YAG lasers deployed at Troms $\varnothing$, Norway $\left(69.6^{\circ} \mathrm{N}\right.$, 19.2 ${ }^{\circ}$ E). Opt. Express 25, A491-A501 (2017)

11. Li, S.X., Yu, A.W., Krainak, M.A., Bai, Y., Konoplev, O., Fahey, M.E., Numata, K.: Progress on Raman laser for sodium resonance fluorescence lidar. Proc. SPIE 10511, 105111H (2018)

12. Krainak, M.A., Yu, A.W., Li, S.X., Bai, Y., Numata, K., Chen, J.R., Fahey, M.E., Micalizzi, F., Konoplev, O., Janches, D., Gardner, C.S., Allan, G.R.: Progress on laser technology for proposed space-based sodium lidar. Proc. SPIE 10511, 105111E (2018)

13. Walling, J., Peterson, O., Jenssen, H., Morris, R., O'Dell, E.: Tunable alexandrite lasers. IEEE J. Quantum Electron. 16(12), 1302-1315 (1980)

14. McKay, J.A., Wilkerson, T.D.: Diode-pumped alexandrite laser for DIAL and Doppler lidar. Proc. SPIE 3127, 124-132 (1997)

15. Damzen, M.: Diode-pumped Alexandrite laser: a bright prospect for future space Lidar missions. Proc. SPIE 8534B, 81 (2012)

16. Thomas, G.M., Minassian, A., Sheng, X., Damzen, M.J.: Diodepumped Alexandrite lasers in Q-switched and cavity-dumped Q-switched operation. Opt. Express 24(24), 27212-27224 (2016)

17. Munk, A., Jungbluth, B., Strotkamp, M., Hoffmann, H.-D., Poprawe, R., Höffner, J., Lübken, F.-J.: Diode-pumped alexandrite ring laser in single-longitudinal mode operation for atmospheric lidar measurements. Opt. Express 26, 14928-14935 (2018)

18. Strotkamp, M., Munk, A., Jungbluth, B., Hoffmann, H.-D., Höffner, J.: Diode-pumped Alexandrite laser instrument for next generation satellite-based earth observation," International Conference on Space Optics-ICSO 2018, to be published in Proc. SPIE

19. Höffner, J., Strotkamp, M., Munk, A., Jungbluth, B.: Demonstration of a compact and universal Doppler Lidar based on a novel diode pumped alexandrite ring laser. International Conference on Space Optics-ICSO 2018, to be published in Proc. SPIE

20. Munk, A., Strotkamp, M., Walochnik, M., Jungbluth, B., Traub, M., Hoffmann, H.-D., Poprawe, R., Höffner, J., Lübken, F.-J.: Diode-pumped Q-switched Alexandrite laser in single longitudinal mode operation with Watt-level output power. Opt. Lett. 43, 5492-5495 (2018)

21. Munk, A., Jungbluth, B., Strotkamp, M., Hoffmann, H.-D., Poprawe, R., Höffner, J.: Alexandrite laser in Q-switched, single longitudinal mode operation pumped by a fiber-coupled diode module. Proc. SPIE 10896, 1089610 (2019)

22. Wessling, C., Hengesbach, St., Geiger, J., Dolkemeyer, J., Traub, M., Hoffmann, H.-D.: $50 \mathrm{~W}$ passively cooled, fiber coupled diode laser at $976 \mathrm{~nm}$ for pumping fiber lasers using $100 \mu \mathrm{m}$ fiber bundles. Proc. SPIE 6876, 687614 (2008)

23. Nicklaus, K., Morasch, V., Hoefer, M., Luttmann, J., Vierkötter, M., Ostermeyer, M., Höffner, J., Lemmerz, C., Hoffmann, D.:
Frequency stabilization of Q-switched Nd:YAG oscillators for airborne and spaceborne lidar systems. Proc. SPIE 6451, 64511L (2007)

24. Hahn, S., Bode, M., Luttmann, J., Hoffmann, H.-D.: FULAS: high energy laser source for future lidar applications. Proc. SPIE 10562, 105620P (2017)

25. Ehret, G., Bousquet, P., Pierangelo, C., Alpers, M., Millet, B., Abshire, J.B., Bovensmann, H., Burrows, J.P., Chevallier, F., Ciais, P., Crevoisier, C., Fix, A., Flamant, P., Frankenberg, C., Gibert, F., Heim, B., Heimann, M., Houweling, S., Hubberten, H.W., Jöckel, P., Law, K., Löw, A., Marshall, J., Agusti-Panareda, A., Payan, S., Prigent, C., Rairoux, P., Sachs, T., Scholze, M., Wirth, M.: MERLIN: a French-German space lidar mission dedicated to atmospheric methane. Remote Sens. 9, 1052 (2017)

26. Löhring, J., Winzen, M., Faidel, H., Miesner, J., Plum, D., Klein, J., Fitzau, O., Giesberts, M., Brandenburg, W., Seidel, A., Schwanen, N., Riesters, D., Hengesbach, S., Hoffmann, H.-D.: Key optical components for spaceborne lasers. Proc. SPIE 9730, 973000 (2016)

27. Russbueldt, P., Hoffmann, H.-D.: Innoslab amplifiers. IEEE J. Sel. Top. Quantum Electron. 21, 447 (2015)

28. Siegmann, A.E.: Lasers, pp. 607-613. University Science Books, Sausalito (1986)

29. Hauck, R., Kortz, H.P., Weber, H.: Misalignment sensitivity of optical resonators. Appl. Opt. 19(4), 598-601 (1980)

30. Magni, V.: Resonators for solid-state lasers with large-volume fundamental mode and high alignment stability. Appl. Opt. 25(1), 107-117 (1986)

31. Magni, V.: Multielement stable resonators containing a variable lens. J. Opt. Soc. Am. A 4, 1962-1969 (1987)

32. Fricke-Begemann, C., Alpers, M., Höffner, J.: Daylight rejection with a new receiver for potassium resonance temperature lidars. Opt. Lett. 27, 1932-1934 (2002)

33. Höffner, J., Lübken, F.-J.: Potassium lidar temperatures and densities in the mesopause region at Spitsbergen $\left(78^{\circ} \mathrm{N}\right)$. J. Geophys. Res. D20, 112 (2007)

34. Lautenbach, J., Höffner, J.: Scanning iron temperature lidar for mesopause temperature observation. Appl. Opt. 43, 4559-4563 (2004)

35. Alpers, M., Höffner, J., von Zahn, U.: Sporadic Fe and E layers at polar, middle, and low latitudes. J. Geophys. Res. 99(A8), 14971-14985 (1994)

36. Lübken, F.-J., Höffner, J., Viehl, T.P., Becker, E., Latteck, R., Kaifler, B., Murphy, D., Morris, R.J.: Winter/summer transition in the Antarctic mesopause region. J. Geophys. Res. Atmos. 120, 12394-12409 (2015)

37. Gerrard, A.-J., Kane, T.-J., Meisel, D.-D., Thayer, J.-P., Kerr, R.-B.: Investigation of a resonance Lidar for measurement of thermospheric metastable helium. J. Atmos. Sol. Terr. Phys. 59(16), 2023-2035 (1997)

Publisher's Note Springer Nature remains neutral with regard to jurisdictional claims in published maps and institutional affiliations. 